\title{
Pomza Ocağı Atıklarının Așınma ve Sertlik Değerlerine Etkileri
}

\author{
Can Erenson ${ }^{1 *}$, Murat Kalkan ${ }^{2}$ \\ $\mathbf{1}^{*}$ Aksaray Üniversitesi, Mühendislik Fakültesi, İnşaat Mühendisliği Bölümü, Aksaray, Türkiye, (ORCID: 0000-0002-6616-6180), canerenson@aksaray.edu.tr \\ ${ }^{2}$ Aksaray Üniversitesi, Mühendislik Fakültesi, Jeoloji Mühendisliği Bölümü, Aksaray, Türkiye (ORCID: 0000-0002-4350-1599), mkalkan@aksaray.edu.tr
}

(International Conference on Design, Research and Development (RDCONF) 2021 - 15-18 December 2021)

(DOI: 10.31590/ejosat.1039375)

ATIF/REFERENCE: Erenson, C. \& Kalkan, M. (2021). Pomza Ocağı Atıklarının Aşınma ve Sertlik Değerlerine Etkileri. Avrupa Bilim ve Teknoloji Dergisi, (32), 457-462.

$\ddot{O} \mathbf{z}$

Kaynak yetersizliği ve ihtiyaçların artması, atık malzemelerin değerlendirmesinin önemini her geçen gün artırmaktadır. Bu konuda özellikle yapı malzemelerinin üretim ve değerlendirmesinde atık ve kaynak yönetimi, doğa, ekonomi ve zaman açısından çok önemli bir yere sahiptir. Yapılaşmanın sürekli artması taş ocaklarının artmasına sebep olmaktadır. Tüm bu üretim sürecinde kullanım alanı bulunamayan ürünlerin depolanma sorunu inşaat sektöründe sıkça karşılaşılan sorunlardan biridir. Bu kapsamda çalışmada, Aksaray İli Taşpınar Mevki'nde yer alan taş ocaklarının üretim artığı olarak nitelendirdiği atıl elek altı pomza anakaya ve yankaya ürünleri, üretilen bloklar içerisinde ince agrega yerine kullanılmıştır. $15 \times 15 \times 15 \mathrm{~cm}$ boyutlarında küp şeklinde hazırlanan numunelere tek eksenli basınç dayanımı, görünür gözeneklilik, dikey aşındırma ve Schmidt Çekici deneyleri yapılmıştır. Sonuç olarak, üretilen pomza blokların aşınma ve sertlik karakteristikleri dayanım ve boşluk oranı ile ilişkilendirilip yorumlanmıştır. Üretim artığı olarak tanımlanan bu anakaya ve yankaya ürünlerinin yapı malzemelerinde kullanılabilirlik kriterleri bir arada değerlendirilmiştir. Beklenildiği üzere, boşluk oranı arttıkça dayanım ve sertlik değerleri düşmekte ve aşınma değerleri artmaktadır. Bununla birlikte, bu değerlendirilemeyen ürünlerin sektöre kazandırılmak üzere hangi limitlerde kullanılabileceği ve bu kullanımın fiziksel dirence ne kadar etki ettiği gösterilmiş̧tir.

Anahtar Kelimeler: Atık değerlendirme, Dikey aşındırma, Sertlik, Pomza.

\section{Effects of Pumice Quarry Wastes on Abrasion and Hardness Values}

\begin{abstract}
Resource shortage and increasing needs enhanced the importance of the evaluation of waste materials day by day. In this regard, especially in the production and evaluation of building materials, waste and resource management has a very important place in terms of nature, economy, and time-efficient. The continuous increase in construction causes the increase of quarries. The storage problem of products that cannot be used in the production process is one of the frequently encountered problems in the construction industry. In this context, waste undersize pumice products which are described as inert of the quarries located in Aksaray Province Taşpınar Region were used instead of fine aggregates in the produced blocks. In this study, uniaxial compressive strength, apparent porosity, vertical abrasion, and Schmidt Hammer tests were carried out on specimens prepared as cubes of $15 \times 15 \times 15 \mathrm{~cm}$ dimensions. As a result, the abrasion and hardness characteristics of the pumice blocks were correlated and interpreted with the strength and void ratio. The usability criteria of these products which are defined as waste, in building materials were evaluated together. As expected, the strength and hardness values decreased and the abrasion values increased when the void ratio increased. In addition, it was shown in which limits the waste pumice material can be used and how much usage rate affects the physical resistance, to be brought industry.
\end{abstract}

Keywords: Waste utilization, Vertical abrasion, Hardness, Pumice

\footnotetext{
*Sorumlu Yazar: canerenson@aksaray.edu.tr
} 


\section{Giriş}

Endüstriyel hammadde şeklinde pek çok farklı alanda pomza ürünü kullanım yerine göre değerlendirilmektedir. Pomza taşının değerlendireleceği alana göre kırma, eleme ve boyutlandırılması yapılmaktadır. Fakat taş ocaklarında pek çok kez karşılaşıldığı üzere boyutlandırma sürecinden sonra eleğin altında kalan ince taneli atıl ürünler depolarda veya açık alanlarda stok fazlası olarak uzun süre kalmaktadır. Bu bakımdan çalışmada söz konusu bu atıl ürünlerin değerlendirilmesi üzerine üretilen pomza taş tozu ve pomza siltli kumu katkılı blokların mühendislik özellikleri sunulmuştur.

İnşaat sektöründe pek çok farklı alanda değerlendirilme imkânı bulunan pomza, volkanik aktiviteler sonucunda meydana gelen, boşluklu yüzey ve içdokuya sahip, süngerimsi, fiziksel ve kimyasal direnci yüksek, camsı bir volkanik kayaç olarak bilinmektedir. Pomzanın meydana geliş süreci, içerisinde bulundurduğu gazların bünyesinden hızla uzaklaşması ile başlar. Yapısında çok küçük ölçekten çok büyük ölçeklere kadar sayısız gözenek bulundurmaktadır. Pomzanın bu boşluklu yapısına rağmen pek çok avantajı bulundurmasının temelinde söz konusu boşlukların büyük oranda birbirinden bağımsız olması yatmaktadır. Boşlukların bağlantısız olması, iskelet yapının çoğu fiziksel etkene karşı dayanıklılığını sürdürürken aynı zamanda boşlukların düşük geçirgenliği ile termal ve akustik izolasyonu sağlamasını beraberinde getirmektedir.

Orta Miyosen'den Kuvaterner zamanın sonuna kadar Aksaray ve Niğde illeri arasında pek çok volkanik faaliyet olmuştur. Hasandağı - Melendizdağı Volkanizması olarak adlandırılan bu volkanik aktivite sonucu volkan konisi, krater, tüf örtü birimleri ve lav akıntılarının oluştuğu yaklaşık 100 km²'lik alan etkilenmiştir (Ercan, 1985). Aksaray İli çevresinde yer alan pomza oluşumları, Hasandağı Volkanizmasının patlama evresi ürünleri sonucu oluşmuştur. $\mathrm{Bu}$ volkanizmanın ürünleri Kuvaterner yaşlı Hasandağ volkanitleri şeklinde isimlendirilerek farklı evrelerde oluşmuş kül-blok akmaları, döküntü ve akma tüfleri ile andezitik, bazaltik ve riyolitik lavlardan oluşmaktadır (Dönmez vd., 2005). Genellikle açık gri olmakla birlikte belirli kısımlarda krem renkte olan pomzalar atmosfer koşulları altında ani basınç düşüleri sebebiyle genişleyen gazlardan geriye kalan boşlukların oluşturduğu veziküler dokular içermektedir. Diğer bir yandan, kayaç bünyesindeki ana mineralojik bileşim olarak saçılmış şekilde polisentetik ikizlenme gösteren iri plajiyoklas mineraller, biyotit mineralleri ve aksesuar olarak pirit minerali gözlenmektedir (Başpınar ve Gündüz, 2006; Kalkan ve Erenson, 2020).

\section{Materyal ve Metot}

\subsection{Pomza Blokları}

\subsubsection{Pomza Taş Tozu}

Pomza taş tozunun kum içeriği \% 75,79 iken kil-silt karışımı içeriği \%24,21'dir. Laboratuvar deneyleri sonucunda, pomza taş tozunun doğal su içeriği $\left(\mathrm{w}_{\mathrm{n}}\right)$ ve özgül ağırlığı $\left(\mathrm{G}_{\mathrm{s}}\right)$ sırasıyla $\% 7,93$ ve 1,92 olarak bulunmuştur. Etüvde kurutulan pomza taş tozu numunelerinin elek analizi sonuçları Şekil 1'de gösterilmiştir. Sınıflandırmalar, Birleştirilmiş Zemin Sınıflandırma Sistemi yöntemine (USCS) göre yapılmıştır (Stevens, 1982; Das, 2016). Buna göre, pomza taş tozunun SM-SC karışımları (kum-kil-silt karışımları) olduğu tespit edilmiştir.

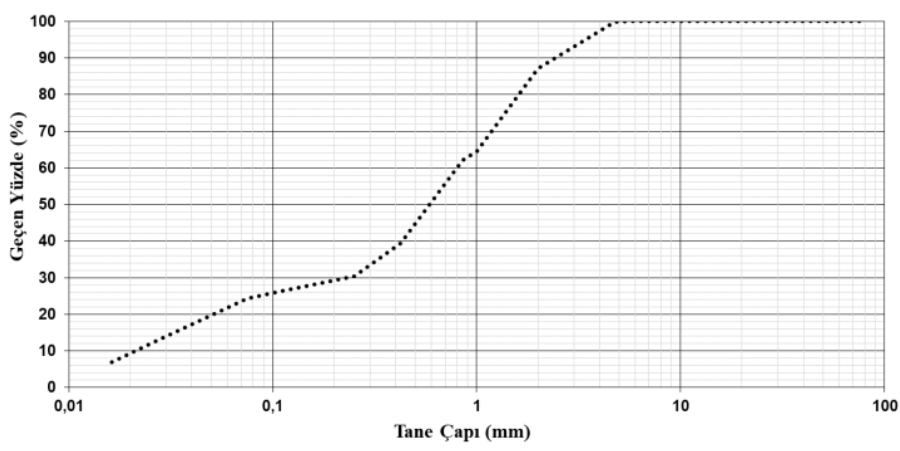

Şekil 1. Pomza Taş Tozunun Elek Analizi Sonucu

\subsubsection{Pomza Siltli Kumu}

Pomza siltli kumu numunesinin kum içeriği \%80.03, kil - silt karışım içeriği ise \%19.97'dir. Analizler sonucunda pomza siltli kumunun doğal su içeriği $\left(\mathrm{w}_{\mathrm{n}}\right)$ ve özgül ağırlığ $\left(\mathrm{G}_{\mathrm{s}}\right)$ sırasıyla $\% 7,60$ ve \%2,25 olarak bulunmuştur. Etüvde kurutulan pomza siltli kumu numunelerinin elek analizi sonuçları Şekil 2'de gösterilmiştir. Sınıflandırma, Birleştirilmiş Zemin Sınıflandırma Sistemi yöntemine (USCS) göre yapılmıştır (Stevens, 1982; Das, 2016). Buna göre, pomza siltli kumunun da SM-SC karışımları (kum-kil-silt karışımları) olduğu tespit edilmiştir.

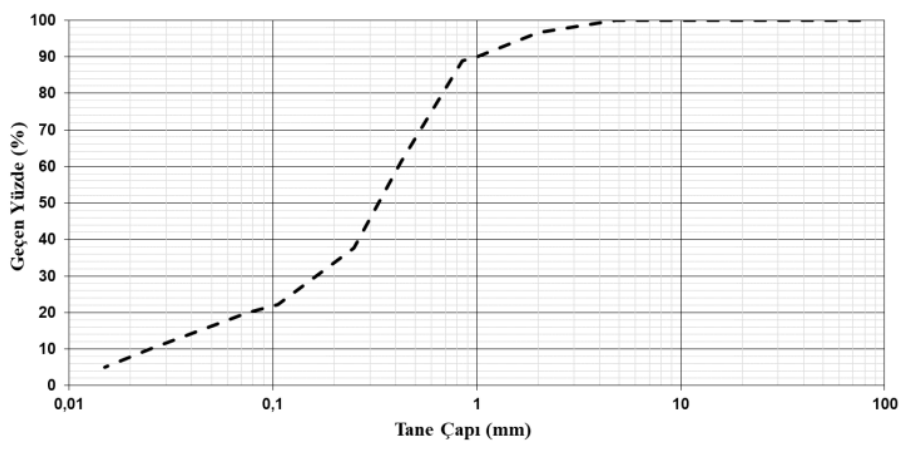

Şekil 2. Pomza Siltli Kumunun Elek Analizi Sonucu

\subsubsection{Agregalar}

Elek analizi sonucunda GP olarak sınıflandırılan agregaların çakıl oranı \%99,5 iken kum içeriği \%0.5 olarak belirlenmiştir (Şekil 3). Agregalar yıkanarak ve kurutularak hazırlanmıştır. Ayrıca, sert, dayanıklı ve standartlara göre beton üretiminde kullanılabilecek kalitededir (TS EN 706, 2009; ASTM C33M-08, 2008).

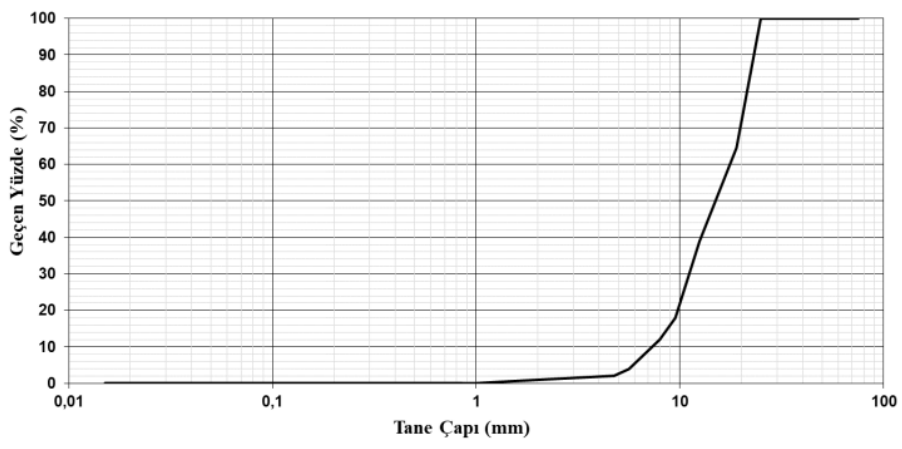

Şekil 3. Agregaların Elek Analizi Sonucu 


\subsection{4. Çimento}

$\mathrm{Bu}$ araştırmada kullanılan çimento puzolaniktir. Kalite ve uygunluk kriterlerine uygundur (BS 196-5, 2011, TS EN 196-1, 2009; TS EN 196-2, 2002; TS EN 197-1, 2012; TS EN 197-2, 2015). Bileşimi, \%54 Portland çimentosu klinkeri, \%36 tras, \%5 kalker ve $\% 5$ alçıtaşı içerir. Çimentonun mühendislik özellikleri Tablo 1'de gösterilmiştir.

Tablo 1. Puzolanik Çimentonun Mühendislik Özellikleri

\begin{tabular}{c|c}
\hline Özellik - İçerik & Değer \\
\hline Kükürt trioksit $\left(\mathrm{SO}_{3}\right)$ & $\leq 3.45 \%$ \\
\hline Klor $\left(\mathrm{Cl}^{-}\right)$ & $\leq 0.1 \%$ \\
\hline Dayanım $(28$ gün $)$ & $\geq 32.5 \mathrm{MPa}-\leq 52.5 \mathrm{MPa}$ \\
\hline Özgül yüzey & $4200-5200 \mathrm{~cm}^{2} / \mathrm{gr}$ \\
\hline Yoğunluk & $2.70-2.85 \mathrm{gr} / \mathrm{cm}^{3}$ \\
\hline
\end{tabular}

\subsection{Test Ekipmanı ve Deney Prosedürü}

Yığınlar halinde arazide atıl vaziyette bekleyen atık elek altı pomza kümelerinden alınan numuneler, laboratuvar ortamında standart karakteristik silindirik basınç dayanımı C25 referans alınarak ince agregalar yerine ikame malzeme olarak farklı oranlarda kullanılmıştır. 5 farklı içeriğe sahip $15 \times 15 \times 15 \mathrm{~cm}$ boyutlarındaki numuneler 28 günün sonunda tek eksenli basınç testine tabi tutularak C8, C12, C17, C22 ve C25 MPa dayanım değerlerine ulaşmışlardır ve su/çimento oranları sırasıyla 0.81 , $0.78,0.740 .71$ ve 0.61 'dir. İnce agrega yerine ikame malzeme olarak, pomza taş tozu, pomza siltli kumu ve diğer bileşenlerin yüzdece oranlarına göre dayanım ilişkilendirmeleri Şekil 4'te sunulmuştur.

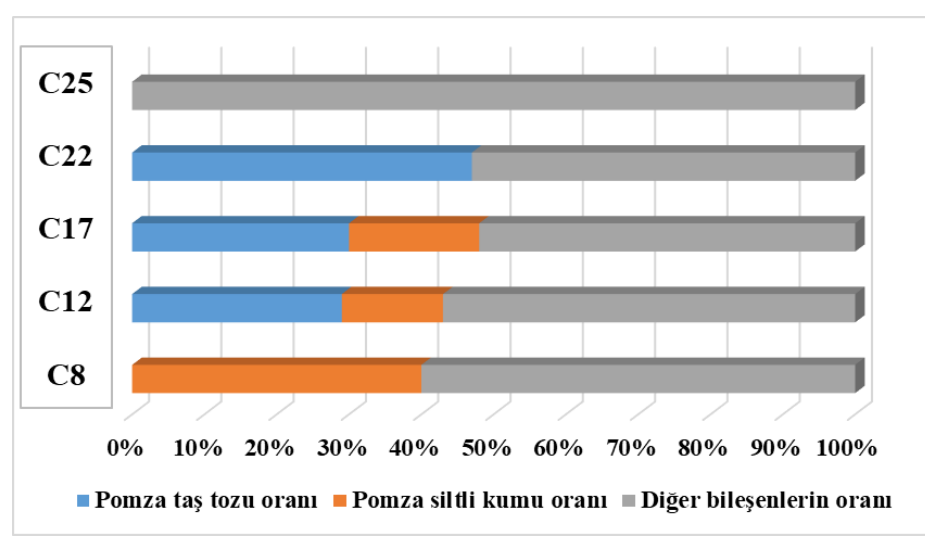

Şekil 4. İçerik-Dayanım İlişkisi

Her dayanım değerine karşılık gelen numunelerin her birinden aynı koşullarda 9'ar numune üretilmiştir. Bunlardan 3'ü basınç testleri için, 3'ü görünür gözeneklilik ve boşluk oranı tayini için, 3'ü ise Schmidt Çekici ve dikey aşındırma testleri için kullanılmıştır. Çalışmada, tüm bu söz konusu deneyler arasındaki ilişki ve bu bağlamdaki atık elek altı pomza ürünlerinin değerlendirilmesi üzerine yorumlar ve kıyaslamalar Araştırma Sonuçları ve Tartışma bölümünde verilmiştir.

\subsubsection{Görünür Gözeneklilik ve Boşluk Oranı Tayini}

Pomza taş tozu ve pomza siltli kumu içeren küp numuneler, ISRM Standardına göre su ile doyurularak 1 saat süreyle 800 Pa'dan daha düşük bir vakum altında hazırlanmıştır (ISRM, 2007). Boşluk hacimleri Eşitlik 1'deki gibi hesaplanmıştır.

Boşlukların Hacmi $\left(V_{v}\right)=\frac{(W s-W d)}{\rho_{\text {water }}}$

Yüzeyi kurutulan numunelerin ağırlıkları ölçülerek Eşitlik 2'ye göre görünür gözenekliliği, Eşitlik 3'e göre boşluk oranları belirlenmiştir (Ulusay, 2014).

Porozite $(n)=\frac{V_{V}}{V} * 100$

Boşluk oranı $(e)=\frac{n}{100-n}$

V: Toplam hacim $\left(\mathrm{cm}^{3}\right)$

$\mathrm{W}_{\mathrm{s}}$ : Suya doygun ağırlık (gr)

$\mathrm{W}_{\mathrm{d}}$ : Kuru ağırlık (gr)

\subsubsection{Dikey Aşındırma Testi}

Dikey aşındırma testi kapsamında, zemin kaplamaları, derz dolgu malzemeleri, sırsız seramik karolar vb. materyallerde bulunan doğal taş veya beton içerikli malzemelerin aşınma direnci tayin edilmektedir. Çalışma kapsamında üretilen pomza bloklar TS 2824 EN 1338 (2005) standardına uygun olarak hazırlanıp hızı dakikada 75 devir olan test cihazında teste tabi tutulmuştur (Şekil 5). Deney sonunda, numune yüzeyi üzerinde açılan yuvaların genişlikleri ölçülmüştür. Ölçümler, oyuğun en geniş kesiti üzerinden yapılmıştır. Her bir deney grubu için üçer numune test edilerek ortalama değerler elde edilmiştir.

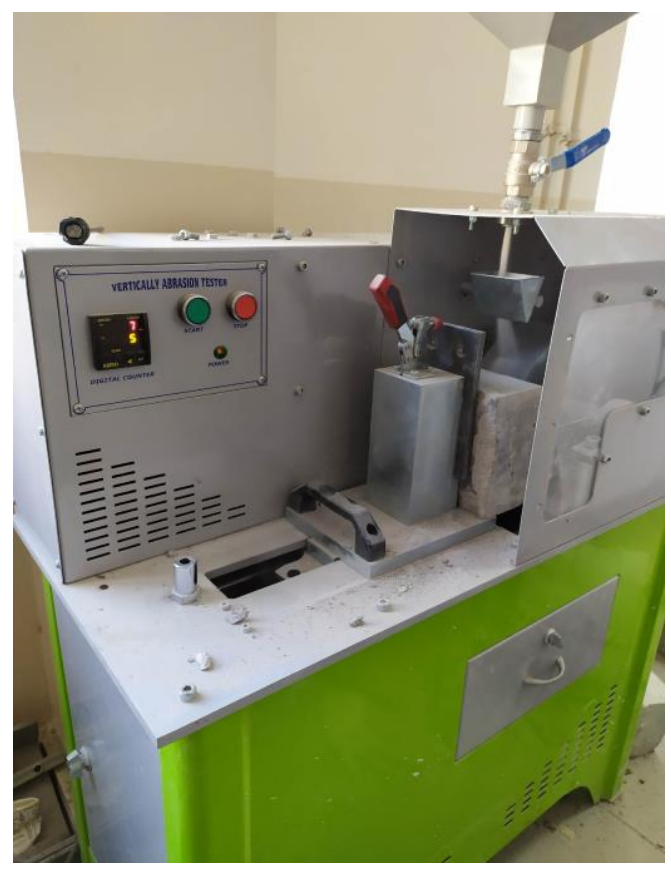

Şekil 5. Dikey Aşındırma Testi 


\subsubsection{Schmidt Çekici Deneyi}

Schmidt Çekici, tahribatsız olarak sertliğin belirlenmesinde kullanılan metotlardan biridir. TS EN 13791 (2019) standardında yöntem, basınç dayanımının yapılar ve öndökümlü beton bileşenlerde yerinde tayini metodu diye adlandırılmıştır. Bu deneyde ise betonlar için kullanılan $\mathrm{N}$ tipi Schmidt Çekici kullanılmıştır (Şekil 6). Burada yük kapasitesi ve gücü Schmidt ölçüm prensiplerine uygun şekilde test edilmektedir. $\mathrm{Bu}$ kapsamda, test çekicinin bloğa çarpıp blok sertliği ve karakteristiğine göre geri sıçrama $(\mathrm{R})$ büyüklüğü tespit edilir. $\mathrm{Bu}$ çerçevede R değeri, granülometri, su / çimento oranı, malzeme yoğunluğu, malzeme türüne bağlı boşluk kaynaklı hava içeriği, fiziksel ve kimyasal dış etkilere karşı göstereceği direnç vb. etmenlere bağlı olarak değişmektedir. Çalışmada yürütülen deneylerde her test yüzeyi için on farklı okuma yapılmış olup her bir deney seti için üçer kere tekrarlanmıştır. Daha sonra, maksimum ve minimum değerler ortalama hesabına alınmadan kalan okumaların aritmetik ortalaması alınmıştır. Sonuç olarak, her bir testte numune yüzeyini temsil eden ortalama geri sıçrama değerleri belirlenmiştir. $\mathrm{Bu}$ deney, her ne kadar uygun korelasyonlar ile blokların dayanımın tahmin edilmesini sağlasa da TS EN 12390-3 (2019) standardında yer alan Betonda Basınç Dayanımı Deneyi'ne alternatif değildir (TS EN 12504-2, 2004). Sadece Schmidt Çekici kullanılarak dayanımı net bir şekilde tayin etmek olanaksızdır. Geri sıçrama değerleri, ölçümlerin alındığı yüzeyin özelliklerine haiz blok numunelerinden elde edilecek sonuçlar ile kalibre edilmeden yorumlanabilir sonuç vermezler. $\mathrm{Bu}$ yüzden, aynı koşullarda hazırlanan küp numunelere ayrıca basınç dayanımı deneyleri uygulanarak değerlendirme kısmında bu deneyde elde edilen sonuçlar üzerinden yorumlamalar yapılmıştır.

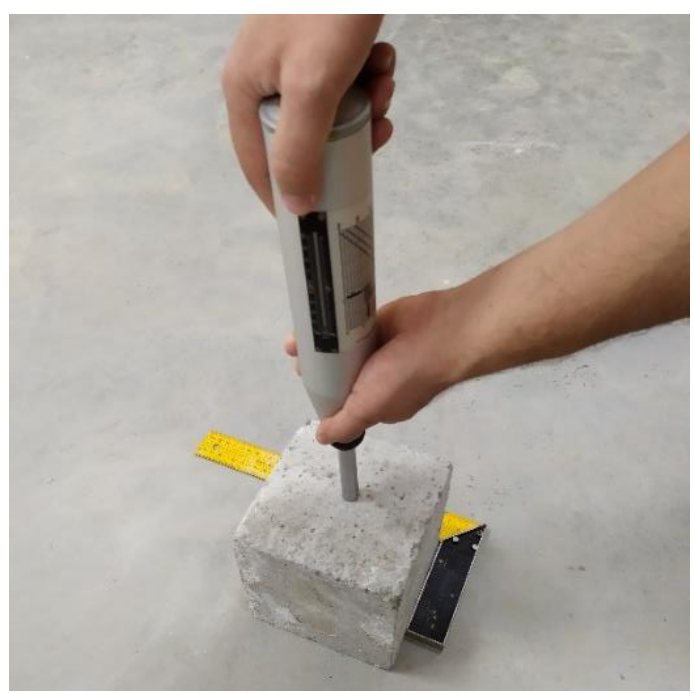

Şekil 6. Scmidt Çekici Deneyi

\section{Araştırma Sonuçları ve Tartışma}

Pomza blokların boşluk oranının belirlenmesi için yapılan görünür gözeneklilik ve boşluk oranı tayini deneylerinde beklenildiği üzere daha düşük dayanımlı numunelerde boşluk oranı daha yüksek olarak tespit edilmiştir. Görünür gözeneklilik deneyi ile boşluk oranının tayin edildiği laboratuvar deneylerinden elde edilen sonuçlar Tablo 2'de verilmiştir. Bu kapsamda, atık pomza içeren blokların boşluk oranı - dayanım grafiği Şekil 7'de verilmiştir. Sonuç olarak, boşluk oranı düşük numunelerin dayanımları, yüksek olanlara kıyasla daha yüksektir.
Tablo 2. Görünür Gözeneklilik ve Boşluk Oranı Tayini Sonuçları

\begin{tabular}{c|c|c}
\hline $\begin{array}{c}\text { Numune } \\
\text { Dayanım (MPa) }\end{array}$ & $\begin{array}{c}\text { Porozite (n) } \\
\mathbf{( \% )}\end{array}$ & $\begin{array}{c}\text { Boşluk Oranı } \\
\text { (e) }\end{array}$ \\
\hline $\mathrm{C} 8$ & 22.4 & 0.29 \\
\hline $\mathrm{C} 12$ & 21.3 & 0.27 \\
\hline $\mathrm{C} 17$ & 18.1 & 0.22 \\
\hline $\mathrm{C} 22$ & 17.9 & 0.21 \\
\hline $\mathrm{C} 25$ & 15.4 & 0.18 \\
\hline
\end{tabular}

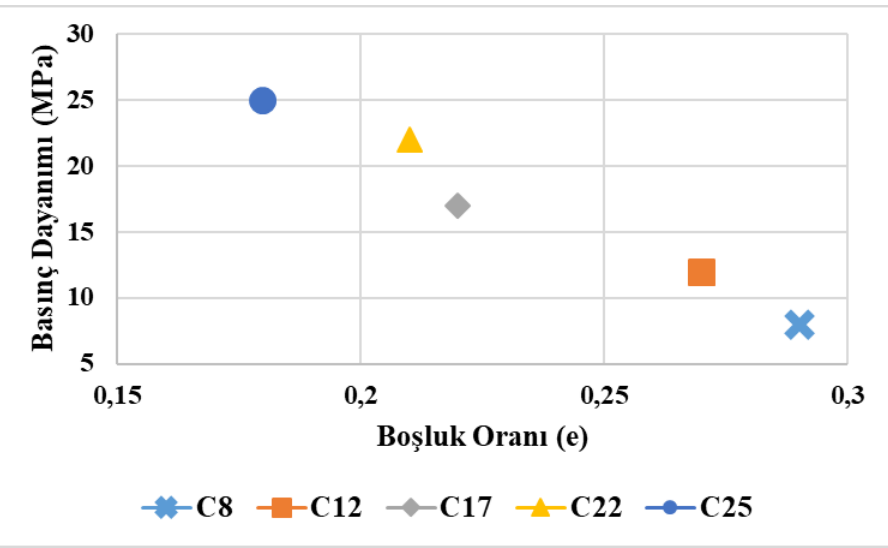

Şekil 7. Boşluk Oranı-Dayanım Grafiği

Schmidt Çekici deneylerinde, elek altı pomza ürünlerini içeren blokların her birinin yüzeylerine üçer vuruş yapılıp ortalamaları alınmıştır. Bu ortalama değerler, her bir dayanım için Tablo 3'te verilmiştir.

Tablo 3. Schmidt Çekici Deneyi Ortalama Değerleri

\begin{tabular}{c|c|c|c|c|c}
\hline Dayanım (MPa) & $\mathbf{C 8}$ & $\mathbf{C 1 2}$ & $\mathbf{C 1 7}$ & $\mathbf{C 2 2}$ & $\mathbf{C 2 5}$ \\
\hline \multirow{4}{*}{$\begin{array}{c}\text { Geri Siçrama } \\
\text { Değeri* } \\
(\mathbf{R})\end{array}$} & 19 & 13 & 21.5 & 22.5 & 24.5 \\
\cline { 2 - 6 } & 18.5 & 21 & 21 & 23.5 & 23.5 \\
\cline { 2 - 6 } & 20 & 21 & 22.5 & 25 & 27 \\
\cline { 2 - 6 } & 17.5 & 20.5 & 22 & 24 & 26 \\
\cline { 2 - 6 } & 20.5 & 23 & 22 & 23.5 & 23 \\
\cline { 2 - 6 } & 20.5 & 24 & 22.5 & 24 & 24.5 \\
\cline { 2 - 6 } & 18 & 20.5 & 21 & 24.5 & 23 \\
\cline { 2 - 6 } & 19.5 & 24.5 & 23 & 22.5 & 21.5 \\
\cline { 2 - 6 } & 18 & 21 & 22.5 & 24.5 & 26.5 \\
\hline $\begin{array}{c}\text { Ortalama } \\
\text { Değerler** }\end{array}$ & 18.95 & 20.95 & 22.05 & 23.7 & 24.3 \\
\hline
\end{tabular}

*Her yüzeye uygulanan 3 vuruşun ortalaması

**Farklı bölgelere vurulan 10 değerin ortalaması 
Dikey aşındırma testi, bu deneyler için ayrılan her 3 numunenin 2 farklı ve karşılıklı yüzeyinin aşındırma diski ile aşındırılması kapsamında yürütülmüştür. Dikey aşındırma testinde ele alınan değerler Şekil 8'de gösterilen oyuğun üç farklı kesitinden alınan genişlikler ve ortalama değerleri ile belirlenmiştir. Her bir deney için aşınan yüzeydeki ortalama oyuk genişlikleri Tablo 4'te verilmiştir.

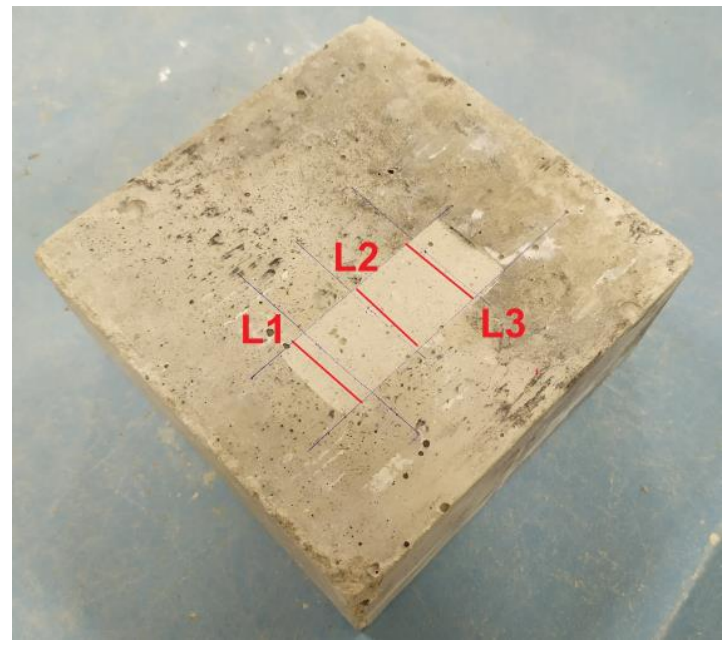

Şekil 8. Numune Üzerinde Aşındırılan Bölge

Tablo 4. Dikey Aşındırma Testi Sonuçları

\begin{tabular}{c|c|c|c|c}
\hline $\begin{array}{c}\text { Dayanım } \\
\text { (MPa) }\end{array}$ & $\begin{array}{c}\mathbf{1 .} \\
\text { Kesit } \\
\text { (L1) }\end{array}$ & $\begin{array}{c}\mathbf{2 .} \\
\text { Kesit } \\
\text { (L2) }\end{array}$ & $\begin{array}{c}\mathbf{3 .} \\
\text { Kesit } \\
\text { (L3) }\end{array}$ & $\frac{\mathbf{L 1 + L 2 + L 3}}{\mathbf{3}}$ \\
\hline $\mathbf{C 8}$ & 32.1 & 34.3 & 36.0 & 34.1 \\
\hline $\mathbf{C 1 2}$ & 27.2 & 23.0 & 29.9 & 26.7 \\
\hline $\mathbf{C 1 7}$ & 19.8 & 16.1 & 19.3 & 18.4 \\
\hline $\mathbf{C 2 2}$ & 10.0 & 15.1 & 13.4 & 12.8 \\
\hline $\mathbf{C 2 5}$ & 0.7 & 0.8 & 0.8 & 0.8 \\
\hline
\end{tabular}

*TS 2824 EN 1338 (2005)

\begin{tabular}{c|c|c}
\hline Sinıf & $\begin{array}{c}\text { Sinıf } \\
\text { gösterimi }\end{array}$ & $\begin{array}{c}\text { Deney sonucu ölçülecek } \\
\text { Değer }\end{array}$ \\
\hline 1 & F & $>24 \mathrm{~mm}$ \\
\hline 3 & H & $\leq 23 \mathrm{~mm}$ \\
\hline 4 & I & $\leq 20 \mathrm{~mm}$ \\
\hline
\end{tabular}

\section{Sonuç}

Çalışmada, pomza blokların değerlendirilmesinde aşınma, sertlik (Schmidt), görünür gözenekliliğin etkisi ve dayanım ile ilişkilendirmelerini kapsamaktadır. Sonuçlar, pomza taş tozu ve pomza siltli kumu içeren bloklar üzerinde yapılan dikey aşındırma testi, Schmidt Çekici deneyi ve görünür gözeneklilik ve boşluk oranı tayini ile belirlenmiştir. Beklenildiği üzere boşluk yapısı arttıkça dayanım, aşınma ve sertlik değerleri düşmektedir. Fakat elek altı olarak atıl halde bekleyen pomza anakaya ve yankaya ürünlerinin çeşitli sektörlerde değerlendirilmesi hususunda belli oranlarda kullanılmasının mümkün olduğu gözlemlenmektedir.
$\mathrm{Bu}$ bakımdan araştırmada, kullanım amacına ve hedeflenen dayanım referansına göre değerlendirilebilmesi çerçevesinde, bloklar içerisinde kullanılan pomza taş tozu ve pomza siltli kumu oranları verilmiştir. İlgili şartların sağlanması durumunda, çalışmada belirlenen oranlara göre hazırlanacak numunelerin deney sonuçları verilerek verilerin sektöre bir rehber niteliğinde olması ve okurların malzeme hakkında bilgi sahibi olması hedeflenmiştir. Çalışma kapsamında saptanan diğer sonuçlar ise aşağıdaki gibidir:

- Numunelerdeki pomza taş tozu ve pomza siltli kumu oranındaki artı̧̧a bağlı olarak numune bünyesindeki yapısal boşluk hacmi artmıştır. Sonuç olarak, 24 saat suda birakılan numunelerden sadece pomza siltli kumu ve pomza siltli kumu - pomza taş tozu karışımı içeren numuneler daha fazla su emmiş ve yüksek porozite değerleri göstermiştir.

- Atık elek altı pomza taş tozu içermeyen standart karakteristik basınç dayanımı C25 olan numune, beklendiği gibi en düşük gözeneklilik değerine sahiptir.

- Sadece pomza taş tozu içeren numunelerin dayanımları, belirli oranda pomza taş tozu - pomza siltli kum karışımı ve sadece pomza siltli kum içeren numunelere oranlara daha yüksek dayanım değerleri vermiştir.

- Yukarıdaki sonuçlara istinaden blokların $\mathrm{R}$ değerleri sadece pomza siltli kum içeren C8 numunesinde boşluk oranı ve görünür gözenekliliğinin fazla olmasından dolayı en düşüktür. Belirli oranda pomza taş tozu ve pomza siltli kumu içeren $\mathrm{C} 12$ ve $\mathrm{C} 17$ dayanımına sahip numunelerin $\mathrm{R}$ değerleri $\mathrm{C}$ ' $\mathrm{e}$ göre yüksek olsa da sadece pomza taş tozu içeren $\mathrm{C} 22$ numunesinin $\mathrm{R}$ değerinden düşüktür. $\mathrm{C} 25$ referans numunesi ise daha az görünür gözeneklilik ve boşluk oranına sahip olduğu için en yüksek R değerine sahiptir.

- Dikey aşındırma testine göre ortalama $20 \mathrm{~mm}$ 'nin altında aşınma değerine sahip olan C22 ve C17 numuneleri 4(I) sınıfinda yer almaktadır. Bu bakımdan bu numuneler, parke taşı, kilit taşı vb. zemin döşemelerinde kullanılmak üzere aşınma limitlerini sağlamaktadır. C12 ve C8 numuneleri ise $1(\mathrm{~F})$ sınıfinda olduğu için zemin döşemelerinde kullanılmak üzere aşınma limitlerini sağlamamaktadır.

Ayrıca, "sıfır atık" projelerinin her geçen gün daha da önem kazandığı bugünlerde, taş ocağı atıklarının da değerlerdirilmesi, katma değeri yüksek, doğayla barışçl, ekonomik ve fonksiyonel uygulamaların önünü açmaktadır. Bu bakımdan, yığınlar halinde depolanan atıl vaziyetteki pomza malzemelerinin de farklı sektörlerde pek çok yönden değerlendirilebilmesi ciddi önem taşımaktadır.

Bilimsel toplumda atık malzemelerin değerlendirilebilmesi için yapılan çalışmaların aynı zamanda ilgili sanayi kollarına da duyurulması daha ileri seviye çalışmaların yapılarak kapsamlı sonuçların elde edilmesini sağlayacaktır. Bununla birlikte alternatif bir yapı malzeme bileşeni olan pomzanın, briket, bordür ve kilit taşı üretimlerinde de etkili bir şekilde değerlendirilebilmesi için farklı çalışmaların da yapılması ve geliştirilmesi gerekmektedir. 


\section{Kaynakça}

ASTM (2008) Standard specification for concrete aggregates, ASTM International C33/C 33M-08.

BS (2011) Methods of testing cement, European Standards, BS EN 196-5.

Başpınar, E., Gündüz, L. (2006) İnşaat endüstrisinde kullanılan pomza agregalarının mineralojik ve petrografik özellikleri. IV. Ulusal Kırmataş Sempozyumu, İstanbul.

Das, B. M. ve Sivakugan, N. (2016) Fundamentals of Geotechnical Engineering, Cengage Learning, United Kingdom.

Dönmez, M., Akçay, A. E., Kara, H., Türkecan, A.,Yergök, A.F. ve Esentürk, K. (2005) 1/100000 Ölçekli Türkiye Jeoloji Haritaları, Aksaray-L32 paftası, MTA., Ankara.

Ercan, T. (1985) Orta Anadoludaki Senoziyik Volkanizması, MTA Yayınları, Ankara, 119-140.

ISRM (2007) The ISRM suggested methods for rock characterization, Testing and Monitoring: 1974-2006, Int. Soc. for Rock Mech. Ankara.

Kalkan, M. ve Erenson, C. Atık elek altı pomza malzemesinin killi zemin ortamlarında mühendislik karakteristikleri bakımından değerlendirilmesi. Bilimsel Madencilik Dergisi, 59(3).

Stevens, J. (1982) Unified soil classification system, American Society of Civil Engineers, 52(12), 61-62.

TS EN. (2002) Methods of testing cement - Part 2: Chemical analysis of cement, Turkish Standards Institution, EN TS 196-2, Ankara.

TS EN. (2004). 12504-2. Testing concrete in structures, Part-2 Non-destructive testing, determination rebound number, Standard.

TS EN. (2005) Zemin döşemesi için beton kaplama blokları gerekli şartlar ve deney metotları, TS 2824 EN 1338 Ankara.

TS EN. (2009) Aggregates for concrete, Turkish Standards Institution, EN TS 706 EN 12620+ A1, Ankara.

TS EN (2009) Methods of testing cement - Part 1: Determination of strength, Turkish Standards Institution, EN TS 196-1, Ankara.

TS EN. (2012) Cement- Part 1: Compositions and conformity criteria for common cements, Turkish Standards Institution, EN TS 197-1, Ankara.

TS EN. (2015) Cement - Part 2: Conformity evaluation, Turkish Standards Institution, EN TS 197-2, Ankara.

TS EN. (2019) Beton - sertleşmiş beton deneyleri - Bölüm 3: Deney numunelerinin basınç dayanımının tayini, Türk Standardları Enstitüsü, TS EN 12390-3, Ankara.

TS EN. (2019). Beton basınç dayanımının, yapılar ve öndökümlü beton bileşenlerde yerinde tayini, Türk Standardları Enstitüsü, TS EN 13791, Ankara.

Ulusay, R. (2014) The ISRM suggested methods for rock characterization, Testing and Monitoring. 